\title{
The Relationship between Foreign Direct Investment and Inflation: Econometric Analysis and Forecasts in the Case of Sri Lanka
}

\author{
A. M. M. Mustafa ${ }^{1}$ \\ ${ }^{1}$ Faculty of Management and Commerce, South Eastern University of Sri Lanka, Sri Lanka \\ Correspondence: A. M. M. Mustafa, Faculty of Management and Commerce, South Eastern University of Sri \\ Lanka, Oluvil, \# 32360, Sri Lanka. E-mail: amustafa@seu.ac.lk
}

Received: March 26, 2019

Accepted: May 7, 2019 Online Published: May 30, 2019

doi:10.5539/jpl.v12n2p44

URL: https://doi.org/10.5539/jpl.v12n2p44

\begin{abstract}
There are several reasons why the dynamic interaction between FDI and inflation must be studied. First, Foreign Direct Investment is found as one of the important determinants of the process of economic growth and development of Sri Lanka. Therefore, the literature empirically examining the causal relationship between the inflation and FDI is significant because the rate of high inflation affects the inflows of FDI inflows into the economy of Sri Lanka and slows down the process of economic growth and development. The main objective of this study is to examine the linkages between FDI and inflation in Sri Lanka for the time periods from year 1978 to year 2017. The dependent variable of the model used in this study is Inflation and the independent variable of the model is FDI (Foreign Direct Investment). The data used in the model are the annual time series collected from Annual Report of Central Bank of Sri Lanka. The tools to analyze the data are graphical representation, Johansen Co-integration test, simple regression model, Residual Analysis, Stability Test, and Granger Causality Test. A long run relationship is found between the variables. The dependent variable: INF - Inflation is inversely related with the independent variable: FDI - Foreign Direct Investment. One-way causal relationship from FDI to INF is ensured. The forecast sample is ranged from 2009 to 2017. The simple regression model affirms the significant impacts of the FDI - Foreign Direct Investment on the INF - Inflation. The forecasting model derived from the simple regression model is rather incompatible to forecast the value of dependent variable (Inflation).
\end{abstract}

Keywords: foreign direct investment, inflation, long-run relationship, regression, forecasting

\section{Background}

Foreign Direct Investment (FDI) has reached historical milestone during past three decades and it has become significant aspect in the developing world. A growing number of developing countries are succeeding in attracting substantial and rising amounts of inward FDI. In both developed and developing countries, policy makers pay attention to achieve high sustainable economic growth with low inflation and it is also used as a poverty reduction strategy (Khan and Senhadji, 2001). The rate of low inflationary pressure is considered as a symptom of economic stability found internally in the host country. The rate of low inflationary pressure in a country lead to increase the rate of return received from FDI. It is found as one of the macroeconomic indicator which is used to measure the macroeconomic stability. And also, it is considered as a symptom of government's willingness so as to balance the budget of the government. Further, it is viewed as the ability of the central bank to conduct appropriate monetary policy. The dynamic contribution of Foreign Direct Investment as a vehicle for economic growth and development has become very important for the developing countries all over the world. It is found that the Foreign Direct Investment is motivated by rate of low level of inflationary pressure in a country. As the rate of inflation is recorded as low in a country, there is a decline in Nominal Interest Rate. Therefore, the cost of capital expenditure is less. The opportunity available for the capital at the cheaper rate is enabling the investors of FDI to found the partners in the host country along with the adequate domestic investment. And also, it is an opportunity that can be used to increase the rate of return from the investment. Thus, the capital available at cheaper rate of interest and the domestic consumption which is higher in the host country due to the lower price levels leads to attract Foreign Direct Investment to stimulate economic growth and development.

\section{Literature Review}

Egwaikhide (2008) studied that inflation attracts FDI inflows into developing countries. The article finds that granger causality test however, proves the absence of any directional causality between inflation and FDI. 
Djokoto (2012) examined the impact of the promotion of investment on the fin low of FDI in the country of Ghana for the time period from year 1970 to year 2009. He found an inverse relationship between the inflationary pressure and FDI.

Igwemeka Ebele Okafor (2016) investigated the relationship between the inflation in the home country and the effect of foreign investment in the home country in the context of Nigeria during the time series from year 1987 to year 2012 by using statistical tools such as Ordinary Least Squared technique, Augmented Dickey Fuller Test, and Granger Causality Test. A direct relationship is found between Foreign Direct Investment and Inflation in Nigeria and the impact of Foreign Direct Investment on the inflation is not significant.

Mohammed Valli and Mansur Masih (2014) attempted to find if a long-run theoretical associationship exists between the inflation and Foreign Direct Investment in South Africa by the use of time series data from year 1970 to 2012. They found a long-run negative relationship between the rate of inflation and Foreign Direct Investment in the country.

\section{Research Problem}

There are several reasons why the dynamic interaction between FDI and inflation must be studied. First, Foreign Direct Investment is found as one of the important determinants of the process of economic growth and development of Sri Lanka. Therefore, the literature empirically examining the causal relationship between the inflation and FDI is significant because the rate of high inflation affects the inflows of FDI inflows into the economy of Sri Lanka and slows down the process of economic growth and development. Therefore, this study raises the research question as "whether FDI inflow is influenced by the inflation in Sri Lankan context?"

\section{Objectives of the Study}

The prime objective of the study is to find the relationship between FDI and inflation in SriLanka between periods 1978 and 2017 using the Bound Test of co-integration. And the specific objectives of this study are: Examine visual inspection (diagrammatic representation) of the relationship between the variables, the existence of a long-run relationship among the variables, the simple regression model and its residual diagnostic tests and examine Granger Causality test to identify the directional relationship.

\section{Methodology}

In this study, Econometric Methodology -Simple Regression and Correlation analysis are used to analyze the data and Ordinary Least Square (OLS) method is used to estimate the parameters of the models. Granger type causality test will be used to identify the direction of casual relationship between FDI and inflation and Unit root test is applied to test stationary properties of each variable. Co-integration analysis is done to examine the long run (LR) relationship between FDI and tourism industry. E-views 9 econometric software and Minitab statistical software were used for the data analysis. While MS Excel is used for preliminary calculations, MS Word was used for the word proceeding of this study. The study uses time series data for the period from 1978 to 2017 . Data relevant to this study were collected from the secondary sources such as International Financial Statistics (IFS), World Investment Report 1990 - 2017, Investors Guide, Central Bank Annual Report 1978 - 2017, Annual Statistical Report of Sri Lankan Tourism 1990 - 2017, and Economic and Social Statistics in Sri Lanka 1990 2017.

\section{Result and Discussions}

Figure 1 below shows the graphical representation of the Foreign Direct Investment from year 1978 to 2017. Up to year 1990, the trend of Foreign Direct Investment over the years concerned is constant and is considerably very less. From year 1990 onwards, the trend of FDI is upward and thereafter there is a sudden downturn in the trend of FDI. From year 1995 onwards, there is a slow upward trend of FDI and from 2005 onwards, there is a sharp increase in FDI. From 2008 onwards up to year 2010, a sudden fall in the FDI is recorded. 


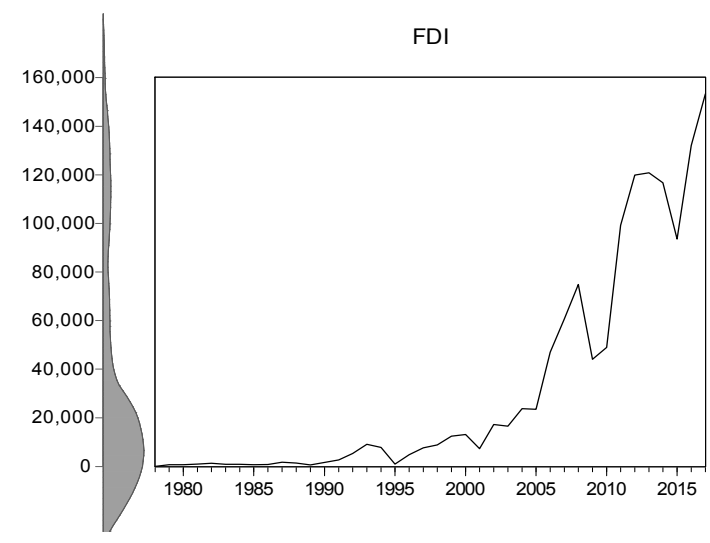

Figure 1. Trend of foreign direct investment

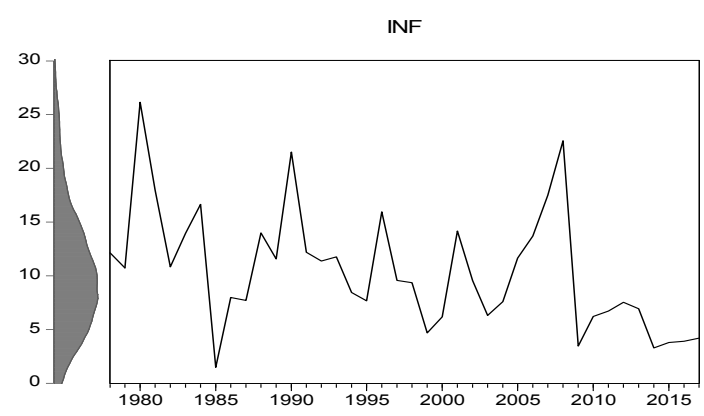

Figure 2. Trend of inflation

In addition, from year 2010 onwards there is a drastic increase in the FDI up to year 2013. And thereafter, up to year 2015 there is drastic decrease found in FDI. Then onwards from 2015, there is a sharp increase in FDI. It is found that there is an overall upward trend in FDI after year 1995 with the slight fluctuations. Figure 2 clearly shows the trend of inflation in Sri Lanka from 1978 to 2017. During the period of 1980the inflation in Sri Lanka is estimated at very high level. It is the highest record with respect to the price level in Sri Lanka. Then, from year 1980, there is a persistent decline in the price level in Sri Lanka. Up to year 1982, a sharp decline in the price level is estimated during this time period. Then, there is a short-term increase in the price level up to 1984. Immediately after that, there is a drastic downfall being found in the inflation in the country. It is observed in the trend of the price level in the country that there is a considerable fluctuation in this trend over the time period from year 1985 onwards to 2004 year. From year 2005, there is a sharp increase found in the inflation and from year 2008, a vertical downfall is found in the trend of price level in the country. Further, the trend of price level from year 2010, it is observed that it is around constant. Visual Inspection for the relationship between Time Series Variables FDI and INF Confidence Ellipse is shown in the following figure 3:

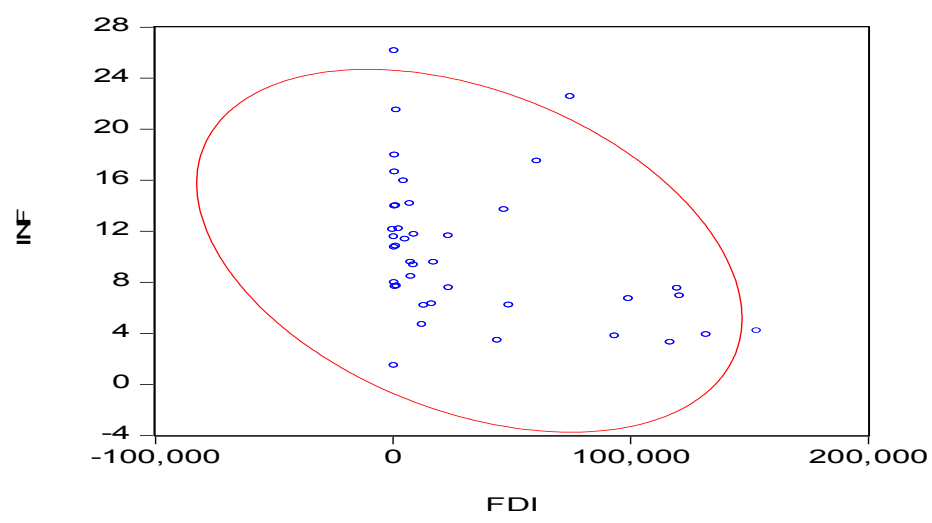

Figure 3. Visual Inspection for the relationship between Time Series Variables FDI and INF

Above figure Graphical presentation of data is very useful to identify the trend and underlying relationship between the two variables FDI and INF. The Confidence ellipse graph shows that relationship between FDI and INF.

Table 1 shows the results of the test of long run relationship of the variables. To test the long run relationship of the variables, the test of co-integration is used in this study. In Table 1, to find out the relationship, Trace Test is used. As per this Trace Test, the criteria of "the value of Trace Statistic should be higher than Critical Value" is fulfilled as the value of Trace Statistic is higher than Critical Value. 
Table 1. Johansen co-integration test (Trace Statistic)

\begin{tabular}{ccccc}
\hline $\begin{array}{c}\text { Hypothesized } \\
\text { No. of CE(s) }\end{array}$ & Eigenvalue & $\begin{array}{c}\text { Trace } \\
\text { Statistic }\end{array}$ & $\begin{array}{c}0.05 \\
\text { Critical Value }\end{array}$ & Prob.** \\
\hline None $^{*}$ & 0.351075 & 18.10638 & 15.49471 & 0.0198 \\
At most 1 & 0.043090 & 1.673737 & 3.841466 & 0.1958 \\
\hline
\end{tabular}

Table 2 shows other results of co-integration test of variables such as Foreign Direct Investment and Inflation in the context of Sri Lanka. According to the test of Max-Eigen, the value of Max-Eigen statistic is 16.43 and the value of Critical Value is estimated at 14.26. Accordingly, the value of Max-Eigen Statistic is higher than the Critical Value at significant value less than 5 percent $(p<5 \%)$.

Table 2. Johansen co-integration test (Max-Eigen)

\begin{tabular}{ccccc}
\hline $\begin{array}{c}\text { Hypothesized } \\
\text { No. of CE(s) }\end{array}$ & Eigen-value & $\begin{array}{c}\text { Max-Eigen } \\
\text { Statistic }\end{array}$ & $\begin{array}{c}0.05 \\
\text { Critical Value }\end{array}$ & Prob.** \\
\hline None ${ }^{*}$ & 0.351075 & 16.43264 & 14.26460 & 0.0224 \\
At most 1 & 0.043090 & 1.673737 & 3.841466 & 0.1958 \\
\hline
\end{tabular}

Table 3. The overall results of Johansson Co-integration

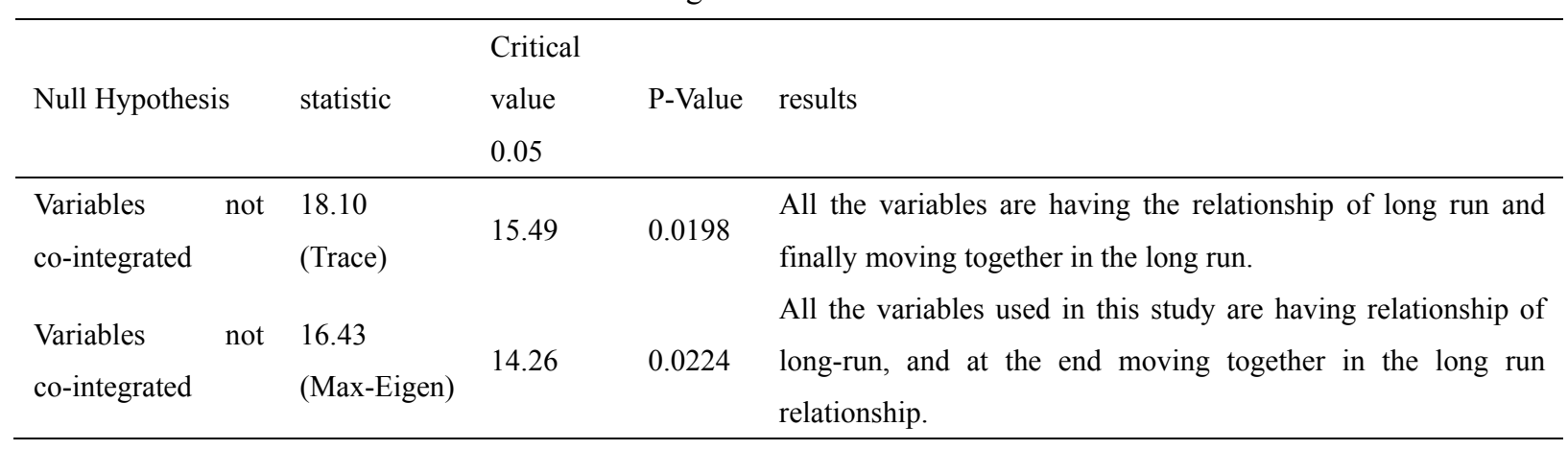

On the basis of the test of Johansen Co-integration shown in Table 3, it is identified that all the two variables used in this study are having the characteristics of long-run relationship, at the end all the variables are moving together. Further, based on this test, a close relationship is ensured between the two variables considered in this study. There is a significant long-run relationship between the variables at $5 \%$ significant level $(p<5 \%)$. It means the null hypothesis of "Variables are not co-integrated" can't be confirmed whereas it can be accepted. Table 4 below shows the results of the simple regression model. In this model, Inflation (INF) is the dependent variable and the Foreign Direct Investment (FDI) is the independent variable. On the basis of the simple regression model, the following estimated model can be constructed:

$$
\text { INF }=3.11-0.10 F D I
$$

The above model estimated is the log-linear simple regression model. The value of coefficient of this model is the coefficient of log-linear coefficient of simple regression model. 
Table 4. The results of the simple regression model

\begin{tabular}{lrcrr}
\hline \multicolumn{1}{c}{ Variable } & Coefficient & Std. Error & t-Statistic & Prob. \\
\hline \multicolumn{1}{c}{ C } & 3.110120 & 0.400691 & 7.761884 & 0.0000 \\
\multicolumn{1}{c}{ LOG(FDI) } & -0.102477 & 0.043729 & -2.343460 & 0.0244 \\
R-squared & 0.126272 & Mean dependent var & 2.194890 \\
Adjusted R-squared & 0.103279 & S.D. dependent var & 0.598387 \\
S.E. of regression & 0.566645 & Akaike info criterion & 1.750538 \\
Sum squared resid & 12.20127 & Schwarz criterion & 1.834982 \\
Log likelihood & -33.01076 & Hannan-Quinn criter. & 1.781070 \\
F-statistic & 5.491805 & Durbin-Watson stat & 1.560446 \\
Prob(F-statistic) & 0.024439 & & \\
\hline
\end{tabular}

As per the results of the above simple regression model, the corresponding value of coefficient of FDI is negative. It means that an inverse relationship is found between the dependent variable (INF - Inflation) and independent variable (FDI - Foreign Direct Investment). Thus, the increase in foreign direct investment leads to decrease in the inflation, or else the increase in the foreign direct investment leads to increase in the inflation in the context of Sri Lanka. Based on the value of coefficient of independent variable in this simple regression model, one percent increase in the foreign direct investment leads to decrease the inflation by 0.10 percent, otherwise one percent decrease in the foreign direct investment leads to increase the inflation by 0.10 percent. The independent variable is statistically significant at less than 5 percent significant level $(p<0.02)$. As such, the alternative hypothesis of "there is a significant relationship between the Foreign Direct Investment and the Inflation" is confirmed. Further, the value of Durbin-Watson Statistic is higher than the value of $\mathrm{R}$ squared $\left(D W>R^{2}\right)$. This nature proves that there is no problem of spuriousness in this simple regression model.The impact of the exogenous variables out of this simple regression model on the dependent variable (INF - Inflation) is estimated at 87 percent. The impact of endogenous variable on the dependent variable (INF - Inflation) is solely estimated at around 13 percent. So that 87 percent of the external factors are to be used to find out the relationship between the inflation and foreign direct investment and the variance shared by the foreign direct investment to influence the inflation in this simple regression model is estimated at around 13 percent. Breusch-Godfrey Serial Correlation LM Test andHeteroskedasticity Test (Breusch-Pagan-Godfrey) are used to find out the characteristics of serial correlation and heteroskedasticity of the residual of the simple regression model used in this study. The results of Breusch-Godfrey Serial Correlation LM Test are shown in Table 6. As shown in the table, the value of probability is used to find out the serial correlation of the residual of the model.

Table 5. Breusch-Godfrey serial correlation LM test

\begin{tabular}{lll}
\hline F-statistic & 0.847610 & Prob. F(2,36) \\
\hline Obs*R-squared & 1.798870 & Prob. Chi-Square(2) \\
\hline
\end{tabular}

The probability Chi-Square value connected to Observed R-squared is estimated at more than 05 percent. As a result, the alternative hypothesis of "the residual is serially correlated" is rejected whereas the null hypothesis is confirmed at higher than 05 percent level $(p=0.4068)$. So that there is an absence of serial correlation found in the residual of the model.

Table 6. Heteroskedasticity test (Breusch-Pagan-Godfrey)

\begin{tabular}{lll}
\hline F-statistic & 0.210003 & Prob. F(1,38) \\
\hline Obs*R-squared & 0.219841 & Prob. Chi-Square(1) \\
Scaled explained SS & 0.493418 & Prob. Chi-Square(1) \\
\hline
\end{tabular}

The results of heteroskedasticity test are shown in Table 6. According to the table, the probability Chi-Square 
related to Observed R-squared is 0.6392 which is more than five percent ( $p>0.05)$. As a result, the null hypothesis of "there is no heteroskedasticity found in the residual" is confirmed as the value of corresponding probability is higher than five percent $(p=0.6392)$. As such, there is no heteroskedasticity found in the residual of the model. In contrast, there is a homoscedasticy found in the residuals. It can be concluded that the trend of the residual are distributed in the same parallel direction. Therefore, the results found from the regression model are not erroneous in its conclusion. The stability of the simple regression log linear model of this study is tested by using Stability Test. In this test, the tool of CUSUM test is used to find out the stability of the model. The graphical representation of the CUSUM test is shown in Figure 4.

This simple long linear regression model lies between 5 percent significant level/boundary confined in dotted two red lines by upper and lower limit. Therefore, this model is stable. That is, there is no any of structural breaks in the trend of the model. Figure 5 shows another test of stability of the log-linear simple regression model used in this study. The test of CUSUM of Squares is used to ensure further stability of the model. In this test also, the model is stable, but during year 1985, there is a slight structural break above the five percent significant level.Thereafter, the model is stable throughout the rest of the annual time series. It can be concluded that in those two tests such as CUSUM and CUSUM of Squares, the log-linear simple regression model is considerably stable with the minimum structural breaks.

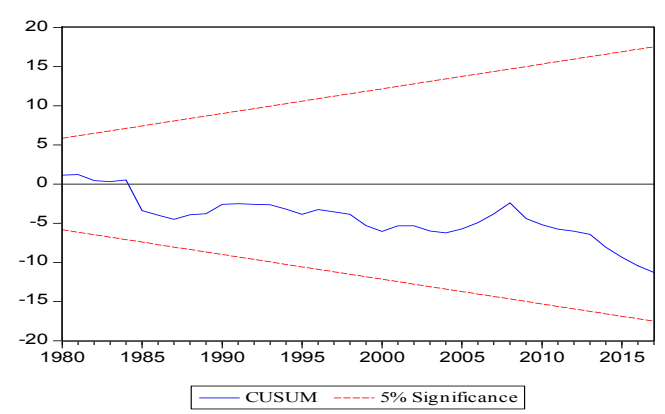

Figure 4. CUSUM test

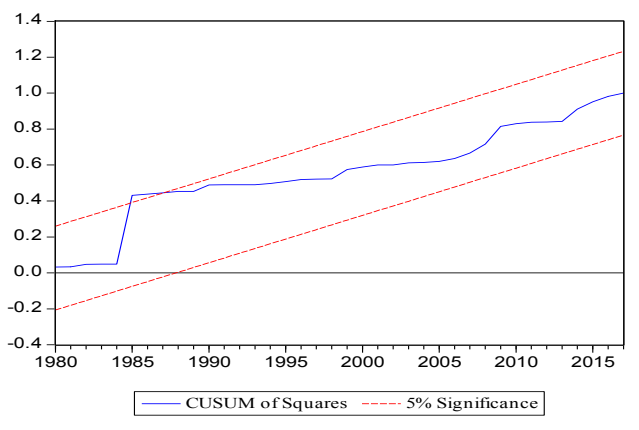

Figure 5. CUSUM of squares test

The results of Granger Causality Test are shown in Table 7. As per Table 7, one-way causal relationship between FDI - Foreign Direct Investment and INF - Inflation is ensured. The null hypothesis of "LOG(FDI) does not Granger Cause LOG(INF)" can be rejected as the value of probability is less than 5 percent. Therefore, the alternative hypothesis of "LOG(FDI) does Granger Cause LOG(INF)" is confirmed at less than 05 percent significant level $(p=0.0426)$.

Table 7. Results of Granger Causality Test

\begin{tabular}{ccc}
\hline Null Hypothesis: & F-Statistic & Prob. \\
\hline LOG(FDI) does not Granger Cause LOG(INF) & 4.42084 & 0.0426 \\
LOG(INF) does not Granger Cause LOG(FDI) & 0.11109 & 0.7408 \\
\hline
\end{tabular}

Accordingly, Foreign Direct Investment - FDI causes Inflation - INF. That is, due to the changes in the foreign direct investment, there is an impact on the inflation.

Forecasting regression model used in this study is also analyzed in terms of forecasting. Under this forecasting, the simple regression model is converted into the dynamic model by adding one more independent variable of INF (-1). It means that the dependent variable (inflation) of this simple regression model is used as one of the independent variables by one period of lag. The time series data used in this dynamic model covers the annual data from 1977 to 2008. The rest of the annual time series data from 2009 to 2017 (10 years) is used for the test of forecasting of the dependent variable (inflation). As a result, the forecast sample is from 2009 to 2017 as shown in the evaluation of the forecasting diagram. Accordingly, the regression equation of dynamic model used in this study to forecast is denoted as EQ1_INFF. Further, this forecasting model is free from serial correlation. 


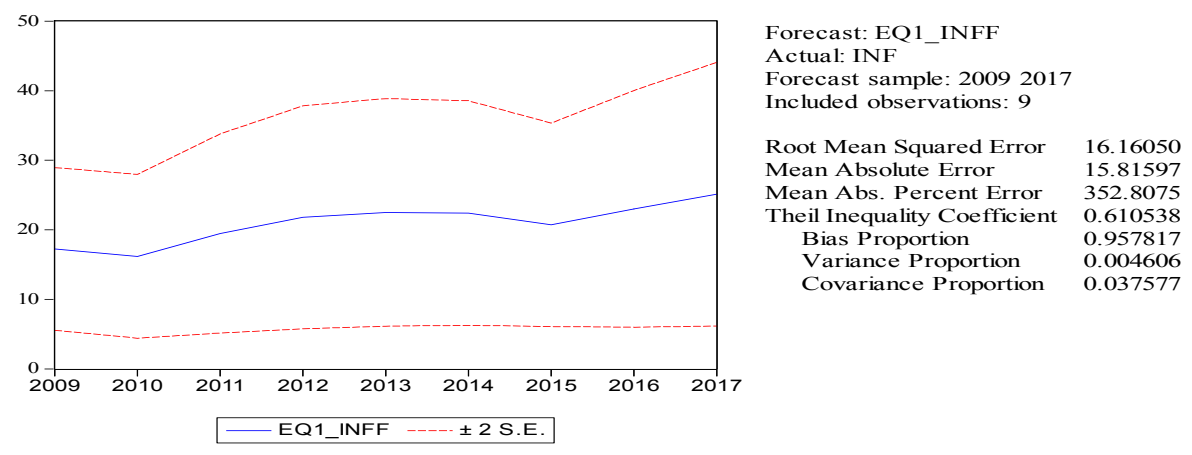

Figure 6. Forecasting EQI_INFF

In the above figure 6, the Root Mean Square Error (RMS Error), Theil Inequality Coefficient (Bias Proportion, Variance Proportion, Covariance Proportion) are studied to analyze the forecasting of the respective model. The blue curve in the above diagram represents the trend of forecasting regression dynamic model (EQ1_INFF). This blue curve is located between 95 percent of confidence interval (between the two red colour curves). The value of Root Mean Square Error represents the gap between the actual dependent variable (INF - Inflation) and forecasting dependent variable (EQ1_INFF - Forecasting Inflation). The value of Root Mean Square Error is estimated at 16.16050. The higher is the value of the Root Mean Square Error, the higher is the gap between the value of actual dependent variable and the value of forecasting dependent variable. In contrast, the lesser is the value of the Root Mean Square Error, the lesser is the gap between the value of actual dependent variable and the value of forecasting dependent variable. The value of actual dependent variable and the forecasting value of dependent variable move together when the value of Root Mean Square Error is nearing to zero.

Another criterion to analyze the forecasting is the value of Theil Inequality Coefficient (U). If the value of Theil Inequality Coefficient is equal to zero, both of the value of actual dependent variable (INF - Inflation) and the value of forecasted dependent variable are same. As a result, both of them are moving together. In addition, they are fitted perfectly. That is, there is error free nature between the value of actual dependent variable and the value of forecasted dependent variable (INF - Inflation). Therefore, the power of predictability of the forecasting model is best. If the value of Theil Inequality Coefficient is equal to one, the power of predictability of the forecasting model is poorest. The value of this coefficient is always between zero to one. If the value of this coefficient is closer to zero, the power of predictability is higher and if the value of the coefficient is close to one, the power of predictability of this model is poor. In the forecasting model used in this study, the value of Theil Inequality Coefficient is 0.610538 which is close to the value of one. Other aspects of the criterion of Theil Inequality Coefficient are Bias Proportion (Bias), Variance Proportion, and Covariance Proportion. Of these aspects, Bias Proportion is primarily studied. This Bias Proportion is also called as Systematic Error. The Bias Proportion evaluates the gap between the value of mean actual dependent variable and the value of mean predicted dependent variable. In this forecasted model, the value of Bias Proportion is 0.957817 (95.78\%). The gap between the value of actual dependent variable and the value of predicted dependent variable is $95.78 \%$. This percent of gap $(95.78 \%)$ between these two values is very higher. 


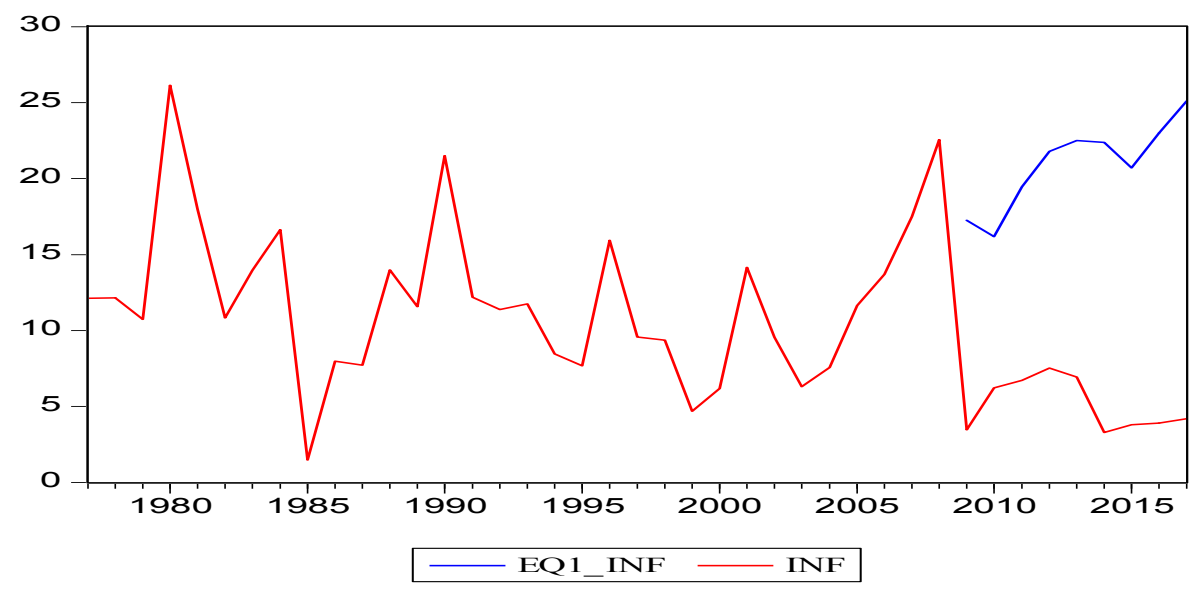

Figure 7. Trend of Forecasting of EQI_INFF and INF

Figure 7 shows the trend of actual value of dependent variable (INF - Inflation) in the red colour curve whereas the blue curve (EQ1_INF) represents the forecasting trend of the dependent variable (Inflation) after year 2009 to 2017. It is seen that the value of actual dependent variable is located considerably far away from the value of forecasting dependent variable.

\section{Findings and Conclusion}

The first specific objective of this study is to examine visual inspection for the relationship between the variables such as INF - Inflation and FDI - Foreign Direct Investment. Up to year 2005 from year 1978 in the context of Sri Lanka, there is very slight fluctuation found and 2005 onwards there is a considerable vertical and sharp increase in FDI along with a number of drastically vertical decreases in FDI. In case of INF - inflation in the context of Sri Lanka, it is found that the trend of inflation throughout the annul time series from 1978 to 2017 is in a cyclical process with a considerable number of fluctuations. It is same as the deterministic trend in its characteristics.

The second specific objective of this study is to find out the long run relationship of the variables used in this study. As per the Johansen Co-integration test, the long-run relationship of all the variables is ensured by this test. The specific objective is to analyze the simple regression model and its residual diagnostic tests. An inverse relationship is found between the dependent variable (INF - Inflation) and independent variable (FDI - Foreign Direct Investment). one percent increase in the foreign direct investment leads to decrease the inflation by 0.10 percent, otherwise one percent decrease in the foreign direct investment leads to increase the inflation by 0.10 percent. The alternative hypothesis of "there is a significant relationship between the Foreign Direct Investment and the Inflation" is confirmed. The impact of endogenous variable on the dependent variable (INF - Inflation) is solely estimated at around 13 percent.

It is found that the predictive power of forecasting model derived from the simple regression model used in this study is very poor. It can be concluded that the trend of the residual are distributed in the same parallel direction. Therefore, the results found from the regression model are not erroneous in its conclusion. There is no any of structural breaks in the trend of the model. The log-linear simple regression model is considerably stable with the minimum structural breaks.

The fourth objective of this study is to examine Granger Causality test to identify the directional relationship. One-way causal relationship from FDI - Foreign Direct Investment to INF - Inflation is ensured. It is found that there is an absence of serial correlation found in the residual of the model. It can be concluded that the Johansen Co-integration test confirms the long run relationship. The simple regression model affirms the significant impacts of the FDI - Foreign Direct Investment on the INF - Inflation. The model used in this study is stable. It is concluded that the forecasting model derived from the simple regression model used in this study is rather incompatible to forecast the value of dependent variable (Inflation).

\section{Recommendation}

Findings of this study will pave the way for the stakeholders such as policy makers, politicians, the governing bodies of Sri Lanka, entrepreneurs, and the apex of the financial institution regulating the inflationary pressure in 
Sri Lanka in order to find and understand the impact of Foreign Direct Investment on the inflationary pressure in the context of Sri Lanka. The significant role played by the Foreign Direct Investment to minimize the domestic persistent increase in the price level can be made aware among the respective stakeholders in the country.

\section{References}

Central Bank of Sri Lanka. (2016). Economics and Social Statistics of Sri Lanka. Colombo: Central Bank of Sri Lanka.

Djokoto Justice, G. (2012). The effect of Investment Promotion on Foreign Direct Investment Inflow into Ghana. International Business Research, 5(3). https://doi.org/10.5539/ibr.v5n3p46

Egwaiklinde. (2008). Exchange Rate Volatility, Inflation Uncertainty and Foreign Direct Investment in Nigeria. Bostwana Journal of Economics, 5(7).

Jayasekara, S. (2014). Determinants of foreign direct investment in Sri Lanka. Colombo. University of Ruhuna. https://doi.org/10.4038/jur.v2i1-2.7849

Khan, M., \& Senhadji, A. S. (2001). Threshold Effects in the Relationship between Inflation and Growth, IMF Staff Papers, 48, No. 1. https://doi.org/10.5089/9781451853339.001

Mohammed, V., \& Mansur, M. (2014). Is there any causality between inflation and FDI in an 'inflation targeting' regime? Evidence from South Africa, MPRA Paper No. 60246. Retrieved from https://mpra.ub.uni-muenchen.de/60246/

Okafor, I. E. (2016). The Impact of Foreign Investments on Domestic Inflation in Nigeria: A Disaggregated Analysis. IOSR Journal of Economics and Finance, 7(2), 25-32. Retrieved from www.iosrjournals.org

\section{Copyrights}

Copyright for this article is retained by the author(s), with first publication rights granted to the journal.

This is an open-access article distributed under the terms and conditions of the Creative Commons Attribution license (http://creativecommons.org/licenses/by/4.0/). 